\title{
Public participation and the co-production of open scientific knowledge: What is at stake?
}

\author{
Hugo Ferpozzi a,b \\ ${ }^{a}$ University of Buenos Aires, Argentina \\ E-mail: hugo.ferpozzi@gmail.com \\ ${ }^{\mathrm{b}}$ Centre for Science, Technology and Society, Valentín Virasoro 732, 1405 Ciudad de Buenos Aires, \\ Argentina
}

\begin{abstract}
Open access is vindicated across diverse areas of scholarly practice, where it is often expected to overcome the material and symbolic barriers that stand in the way of knowledge circulation. However, whether openness is ultimately a good thing or not also seems to depend on which kind of knowledge is being opened and for whom. In this paper I draw on different areas of science, technology and society studies (STS) to suggest that the mainstream views on open access validate practices that may also constrain the possibilities of addressing social needs via scientific knowledge. Building on the case of open access for drug development initiatives in the field of neglected tropical diseases, I elaborate on the different forms of engagement and exclusions that persist in spite of supporting open access to the research data. Two ideas derived from STS are central to this critique: cognitive exploitation (processes through which third-parties turn non for-profit knowledge outputs into profits) and the relations between central actors and peripheries of scientific production. My claim is that the lack of capacities and the interposition of international, biologically-centered research agendas - not access restrictions per se - can hinder the utilization of locally applicable knowledge, deterring public participation in disadvantaged contexts.
\end{abstract}

Keywords: Participation, open access, co-production of knowledge, policy, discourse, drug development, neglected diseases

\section{Introduction}

Open science is a difficult thing to argue against. Scientific knowledge has long been idealized as a universal undertaking, and the movement towards opens science presents itself as something that reinforces the distinct universal quality of science, transcending individual ownership and operating, at the same time, as context-free accounts of the reality. In this paper I put forward a critique to the dominant views on science and open access; that is, a critique to the mainstream discourses based on "universalizing" conceptions about scientific openness. My critique will be structured around two points: The first is that the exclusiveness of scientific knowledge can, to some extent, be realized in spite of formal open access. The second is that the possibilities of producing and effectively utilizing scientific knowledge are necessarily context-dependent.

To convey this critique to the intended qualities of open science I draw chiefly on proposals stemming from the field of science, technology and society studies (STS) and from the sociology of scientific knowledge. In broad terms, these proposals intend to account for the actual dynamics of knowledge production and use of scientific knowledge, rather than the ones idealized in the scientific ethos [35] and reproduced in the mainstream views [38]. In this sense, STS studies offer a conceptual lens to identify the implications of de facto ownership and contextual factors that come with scientific openness, especially 
in contexts marked by asymmetrical relations and political and material inequalities: more specifically, I rely on the concept of cognitive exploitation [27] and elaborate on the dynamics between centers and peripheries $[16,24,26]$, building on the case open-access drug development initiatives targeting neglected and poverty-related diseases. The data comes from my doctoral dissertation [19] and from the outputs of the Open and Collaborative Science in Development Network project "Can open and collaborative science meet social needs?", concerned mainly with the case of Chagas disease research.

Overall, these lines of enquiry are aimed at advancing on diverse modes of participation and exclusion that are usually not taken into consideration as part of the outcomes and impacts of open science. But they also seek to understand (and eventually foster) the participation of diverse stakeholders in the processes of producing scientific knowledge that can effectively address social issues.

The remainder of this paper will be organized as follows: After this introduction, the second section presents the case study, centered around Chagas and other neglected tropical diseases. The first subsection within the presentation of the case study highlights forms ownership and exclusion that subsist together with scientific openness, rather than in spite of it; the second subsection goes on to elaborate on the concept of cognitive exploitation as an analytical tool that accounts for the processes, contexts, and the role of very diverse actors involved in knowledge production and use, while at the same time taking into account its material dimension. The third section discusses the notion of participation usually conveyed with the mainstream literature and discourses on open science, moving the focus from the problem of access to the problem of processes, skills, and practices. The paper closes by presenting its conclusions.

\section{Neglected tropical diseases research and exploitation of open scientific knowledge}

Neglected tropical diseases (NTDs) account globally for aproximately 26 million disability-adjusted life years. The World Health Organization (WHO) lists these as 19 communicable infectious diseases that prevail in tropical and sub-tropical geographies and lack of effective, affordable, widely-available therapeutic options [23]. ${ }^{1}$ One of these diseases, Chagas (or American Trypanosomiasis), is now considered to be a "paradigm" of NTDs [2,36]: while the disease is endemic in the Americas, where affects nearly 10 million individuals - most of them living in rural areas with specific housing and environmental conditions -, demographic processes of the last 40 years have render the disease as a public health concern in urban areas and traditionally non-endemic regions such as Southern Europe, Japan and North America, where it is often associated with immigrant, working-class populations [1,6,14,42,51,53].

Yet, Chagas disease is also a target of sustained international research efforts, aimed at making up for the lack of commercial interest shown by pharmaceutical firms and the resulting scarcity of new medical products such as drugs or vaccines [41,61,62]. Since the 1970s, support for research and development activities in Chagas and other NTDs has come mainly from the Special Programme for Research and Training in Neglected Tropical Diseases (TDR); during the following decades, however, diverse research centers and funding bodies began engaging in tropical, neglected, and poverty-related diseases initiatives, featuring the Rockefeller Foundation, the Bill \& Melinda Gates Foundation, and Doctors without Borders. The broad list of partner and donors also includes universities and government initiatives in both endemic and non-endemic countries as some of its most active stakeholders [31].

\footnotetext{
${ }^{1}$ Snakebite envenoming has been included recently as a non-communicable sickness among the list of NTDs elaborated by the WHO.
} 
The connections between open access and NTDs surface more explicitly towards the year 2006 after the completion of the Trypanosome cruzi Genome project (TcGP), an initiative aimed at mapping the genomic sequence of Chagas' causing organism. Launched almost in parallel with the Human Genome Project, the TcGP was devised in the 1990s as a means for fostering the development of medical applications against Chagas disease. Just as its human counterpart, all the sequences and research data obtained from the TcGP are stored in open access, publicly available databases such as GenBank [9]. Specific open access resources pursuing drug development goals in the field of NTDs developed shortly after: TDR Targets, for instance, was created as a web-accessible open access resource created "to facilitate the rapid identification and prioritization of molecular targets for drug development, focusing on pathogens responsible for neglected human diseases" [32]. The creation of TDR Targets was originally motivated by the TDR working groups, who judged the therapeutic options in the field of neglected diseases to be unsatifactory - especially after the completion of the TcGP and other genome sequencing projects for the pathogens responsible for several NTDs [4,19].

Through the TDR, the WHO managed to set up and define the initial outlines of TDR Targets, but it also expected other stakeholders - representatives from research laboratories and the pharmaceutical industry - to become responsible for the funding and execution of the project. In its initial planning, however, open access was not a requirement specified by the WHO; rather, it was a common proposal made by the leading researchers engaged in the project [4].

\subsection{Production, use, and contextualization of open scientific outputs: Worth for whom?}

Scientific knowledge is expected to contribute to development, and the issue of neglected tropical diseases is one in particular that has relied heavily on technical expertise. The creation of the TDR by the WHO, for instance, was aimed at improving the deficient and donor-dependent situation of public health interventions and research efforts in the field of tropical diseases in the 1970s [46]. But the initial focus of the TDR on basic science had a limiting effect on the approach to NTDs during the following decades: by favoring a biologically minded approach to the problem of NTDs and feeding expectations on the delivery of immediate therapeutic applications - such as drugs or vaccines - [40], the TDR and its working groups directed research priorities towards a portfolio of diseases, rather than making those in need the subject of its priorities [48].

In previous work [19], I argued that this emphasis on the objects of biology, rather than its subjects, could entail other unintended consequences in the context of NTD research. More specifically, I followed the hypothesis according to which open access resources, such as TDR Targets, could be utilized in for-profit operations without providing objective compensation to the original knowledge producers: under this framwork, pharmaceutical firms could, in principle, take advantage of the knowledge outputs produced from publicly funded research efforts without having to face the costs of the initial and more uncertain stages of product development themselves.

In analytical terms, this one-sided utilization of knowledge can be understood as a process of "cognitive exploitation" [27], a phenomenon known to occur historically across diverse fields of technical expertise marked by structural inequalities. For example, amidst the 2006 avian flu pandemic, the Indonesian government faced severe criticism when it decided not to share "their" strains of viruses that caused avian influenza. While this move was seen as a selfish act that jeopardized the development of preventive therapies [20], the Indonesian government argued on the other hand that third parties in developed countries, including pharmaceutical firms, had used their resources to obtain products that were unaffordable for most [52]. 
But cognitive exploitation is not a phenomenon exclusive to the realm of science, nor it pertains only to the development of therapeutic products for populations in need. An typology of the processes involving cognitive exploitation has been proposed by Kreimer and Zukerfeld [27], who classify exploitation according to the kinds of knowledge at stake: while scientific knowledge is one, other kinds include indigenous, laboring, and informational (digital) knowledge. All of these types of exploitation involve non-coercive and one-sided utilization of knowledge; each of them also comprise a specific set of producers and appropriators of knowledge, as well specific sets of mediators and intermediaries that have the ability of "translating" knowledge into applicable forms under specific regulatory frameworks. Here I am concerned with the exploitation of scientific and digital knowledge, as these are the two main types of knowledge involved in the development of genomics resources for drug development. ${ }^{2}$

While cognitive exploitation excludes by definition unlawful means of appropriation, the cases involving digital knowledge often appear to be less controversial that those with the face of "health". One of the central features in the exploitation of digital knowledge is in fact what Zukerfeld [64] understands as its particular material economy; that is, its "double freedom":

whereas the usual voices (from management literature to hackers) emphasize one freedom (the shiny side of copying and sharing informational goods), we think we are unwittingly discussing about two very different but inseparable freedoms. Here is where Marx comes back. One of the key factors for the birth of Capitalism has been what Marx called the double freedom of labor power. On the one hand, the worker is freed from the feudal order, free to move and free to sell his labor-power where, when and how he wants to. By the time of Marx, this had been the only freedom mentioned by Political Economy, Contractualism and Liberalism. But, on the other hand the worker is also freed from the means of production.... Marx highlights the necessity of two contradictory freedoms. In the first case, freedom refers to empowerment; in the second, to the lack of power [p. 146].

The dynamics through which free knowledge is, in these two senses, incorporated into the capitalist machinery is that of "inclusive appropriation": if freely produced digital knowledge is made profitable only by private third-parties, it nonetheless remains non-rivalrous and in many cases also non-exclusive [64]. The processes involving cognitive exploitation, in sum, entail asymmetrical exchanges and take place under contingent legal frameworks that exclude physical coercion as a means. And yet, these processes suggest that beyond formal exclusions to access, there are significant differences in the actual realization of ownership.

The following section unfolds the concept of cognitive exploitation to understand the problem of drug development in the context of NTDs. Using the analytical tools presented with the concept, the focus can thus be moved beyond the problem of formal access to knowledge to include an explanation based on the actors and practices that account for their production and use.

\footnotetext{
${ }^{2}$ The exploitation of these two kinds of knowledge has been extensively addressed in the scholarly literature, although rarely altogether. Lefèvre [29], for instance, posed modern science to be a form of "universal labor": its costs are supported by nonprivate actors during its most "uncertain" phases, but once it becomes stable, the products of scientific labor can be incorporated freely into the productive processes of firms. Terms such as "blind technology transfer" or "leakage" have been proposed by Codner, Becerra \& Díaz [15] to account for the utilization of publicly funded research publications as part of foreign patent files. Other forms of exploitation, which also pertain to the undesired consequences of the research practices in open science, have been objected in the scholarly literature, as well as in documents issued by expert associations and advocacy groups. For example, the International Union for Conservation of Nature [25] has drawn attention to possible abuses of open data in the field of wildlife conservation, while Fecher \& Friesike [18] criticized the utilization of unpaid workforce within in open science. Naturally, there are more extensive debates taking place around the exploitation of digital knowledge. The recurring themes revolve around modes of collaborative production "enabled" by the recent technological and cultural transformations, such as user-generated content, social networking platforms, and free software licenses $[8,17,21,44,50,58,60]$.
} 


\subsection{Cognitive exploitation in the field of neglected tropical diseases research}

Open access to scientific knowledge has become a "public" issue rather recently. These are debates that for the most part stress the problem of access [5,10,37,39,54]. The depictions of open access found among these arenas often convey simplistic ideas of what is at stake with the problem of scientific access, making research data and publications the only output of research that matters. For example and without recurring to the idea of cognitive exploitation -, the publishing industry has been a target of criticism for hindering the dissemination of scientific knowledge, profiting selfishly at the expense of knowledge sharing $[13,43,49]$.

While the current strategies of private publishers may align well with the open access-based business model $[3,56]$, other stages of knowledge production show a very different picture. The case of drug development-related initiatives against NTDs might show this insufficiency in at least three interrelated senses: The first is that genomic databases are both products and means of producing knowledge. As such, this resources encompass different "subtypes" of digital knowledge; there is, for sure, scientific data, but also software and digital contents $[33,64]$. The second is that the potential intermediaries or appropriators of their outputs are primarily pharmaceutical firms, but the motivations sustaining NTD research are chiefly knowledge-driven and supported via government and NGO funding; that is, the ability, interests, and frameworks available to each in order to enforce intellectual property protection are markedly asymmetrical. The third is that NTDs prevail, by definition, in tropical and subtropical contexts, meaning that their incidence is significantly higher in the contexts of development: this "structural" situation not only reinforces its asymmetrical position in relation to the leading centers of scientific and technological development, but also poses very different interests in terms of producing locally applicable knowledge and defining what is ultimately at stake with the issue of NTDs. These diseases constitute a subject for scientific research but also a social and political issue in both endemic and non-endemic contexts that is approached to in very different ways [7,22,30,34,47,59].

The last two senses also imply that by defining the nature of an issue, certain pathways to arriving to solutions appear as possible, while others are shut down or discarded, deemed to be outside the "legitimate" scope of scientific practice. These restrictions to the kinds of knowledge also entail restrictions to the kinds of stakeholders that are likely to be involved in the processes of producing socially applicable knowledge [28]. Often, the considerations on such forms of participation remain outside the legitimate scope of preoccupations within the discourses and conceptions about open science.

The next section will discuss the notion of participation conveyed with the mainstream views to show the possible effects of their limitations.

\section{Public participation and the asymmetrical dynamics of science}

One of the recurring limitations in conceptualizing open science, I argued, is its engagement with the products of science rather than its processes. Fecher \& Friesike [18] offer an initial approach to this limitation by making a distinction between what they call the democratic and public "schools" of open science, respectively. The first school is concerned with access to knowledge; the second is concerned instead with processes and "accessibility".

The idea of accessibility involves at least two different aspects. One aspect refers to the communication and exchanges between lay and scientific actors, a problem often conceptualized in terms of "conveying" scientific knowledge to other audiences [45]. The other aspect refers to the broad label of "citizen 
science"; that is, the participation of non-experts and the "lay" public in the collection and analysis of scientific data.

Yet, this idea of accessibility poses at least two limitations, even when its formulation is more encompassing than the mere concept of access. The first limitation has to do with the skills and capacities that are required to utilize scientific knowledge effectively. Arza \& Fressoli [5], for example, refer to accessibility as "the lack of [other] more informal restrictions, such as the specific skills, capacities, and capital resources required to understand or utilize the products of open science" [p. 3]. Here I would add that it is not just the possession of cognitive or material resources what defines the possibilities of realizing accessibility to scientific knowledge, but also - and perhaps more importantly - symbolic resources; that is, those described by Bourdieu as the social and scientific forms of capital [11].

The second limitation in the idea of accessibility has to do with the stages of knowledge production that enable public participation in science. While citizen science contemplates the participation of nonexperts, the core stages of knowledge production - such as defining the problem and its approach, the research priorities, and type of knowledge outputs expected - remain, for the most, part exclusive to expert circles. ${ }^{3}$

These restrictions to certain expert circles in the processes of setting priorities within research and health agendas has been, as I tried to show, a central feature in the history of the engagemetns between the problem of NTDs and its inteded resolution though the paths of science.

More specifically within the case of drug development in the field of NTDs, the limitations of the views concerned with products have been critically addressed in an document titled "Open source for neglected diseases: Magic bullet or mirage?" [33]. This document, issued by the non-profit organization Results for Development, reviews a series of initiatives linked with drug development to analyze, along with the dimension of access, the dimensions of collaboration and governance. The authors of the documents suggest that there exist significant differences between the dynamics of pharmaceutical business and other domains where open access and practices occur more "naturally" and give rather immediate results. A comparison with the domain of software development may illustrate well the deep contrasts with the pharmaceutical business in terms of risks, development costs, and reliance on intellectual property protection. Software firms, for instance, can rely on copyright protection without major difficulties. But biomedical and pharmaceutical companies depend on extensive clinical trials and costly patent filing processes on the road to taking new products to the market. An open access approach may therefore work well for the "discovery" or "pre-competitive" stages of biomedical research, but has shown rare cases of success for the more critical phases of technology transfer and delivery.

Just as an example, out of 1394 new drugs commercialized between 1975 and 1999, only 16 were destined for NTDs - some of them being modified copies of pre-existing drugs [57,62].

This matrix of contextual obstacles and constrains also suggests that the signifier "open science" conveys limited or at least dissimilar meanings. The authors of the document on open access for neglected diseases illustrate this polysemy by showing the shifting focus of openness among the diverse technical objects involved in drug development:

what is the "source code" at each stage of neglected-disease research? While some working in synthetic biology make the analogy of DNA as source code, the situation is actually more complex.

\footnotetext{
${ }^{3}$ The problem of public participation has long been addressed by the field of STS studies, moving beyond the limited notions of citizen science described above. The myriad of approaches and models proposed to understand and facilitate the engagement of non-experts and scientists in the co-production of scientific knowledge cannot be discussed here in detail, as they normally touch other more general issues that deviate from our preoccupation with open access.
} 
In software, the source code $i s$ the product, while in biology, there are many relevant levels of description and analysis, from DNA to structural genomics, protein interactions, metabolism, and so forth-all interacting in complex ways and requiring a long and expensive process to go from description to approved product [33, p. 3].

Against this backdrop of contextual disadvantages, open access could indeed contribute to increases in productivity by means of facilitating decentralized operations and data sharing, as well as avoiding duplication of research endeavors that entail high commercial risks. However, the aforementioned complexities illustrate more than just a "mismatching" between the mainstream discourses about open science, on the one hand, and its realization through effective scientific practices, on the other. They also suggest that by focusing on the problem of access, the dominant views on open science have omitted the contextual factors that have an effect on the production and utilization of scientific knowledge. In the field of drug development for NTDs, these contextual factors rest on the possession of a broad range of skills and capacities that allow to face changing constraints and regulations, including the ability to engage stakeholders in the different stages of research and development. The case of open access for drug development, in particular in the field of NTDs, shows that there are different dynamics of openness and accessibility exceeding the question of accessing, formally or materially, the products of science.

One of the laboratory directors involved in the development of TDR Targets expressed this broader problem rather bluffly:

I never worked in a [pharmaceutical] firm. But from my meetings, and from all the experience I had with different people at different levels, I believe that there's no market in the first place. So even if firms were interested in us doing all the work and then taking advantage of the results, the day they get those results they are going to realize that they are developing a product that didn't cost them much, but that they have to sell to low-income demographics... Governments have to buy it for them, and every government is different, and so is everything else. I don't know if it's a great business or not... It's different, for example, if someone has diabetes, which needs to be treated permanently... a person suffering from Chagas, instead, you treat them, they're cured, and it's over, they won't be taking that drug ever again... [firms] invest and need to get the money back in ten, twenty years, which is what patents last for.... And even then, I hear this isn't their motivation; the motivation is another kind of intangible benefit, which has to do with public image.... One of the things to blame is excessive regulation... controls, safety issues... there are many and every drug has a problem. So if you have a life or death situation—-say, if you're dying from cancer-, those drugs will get approval.... But for other things they may face many problems [4].

Here the role of mediators and intermediaries - those actors necessary to enable a successful industrialization of scientific knowledge into technological applications - is, again, clearly not limited to the possession of material or cognitive resources alone. The WHO appears in this case as the mediator: it is the obligatory passage point - recurring to Michel Callon's [12] famous terminology - through which pharmaceutical firms, research centers, government offices and funding bodies become, at least in principle, enrolled in collaboration. Pharmaceutical firms, instead, are the intermediaries capable (again, in principle] of introducing the translations necessary for industrializing knowledge. Translation, as it has been shown, entails a few things more than just technical capacities: it entails practical knowhow and expertise on how market and health regulations, public expectations, and intellectual property protection might or might not work for a certain disease, product, population, government, and so on. The constrains of contextual factors was noted by researchers, firm directors, and representatives from health-related NGOs linked to NTD research and development in more or less equivalent terms. But 
the solutions proposed to address these tensions were significantly different in each case - solutions in which the responsibility lies, in the last instance, on another stakeholder that would not fulfill its role [19]. In particular, the WHO has favored, through the TDR, a biomedically-centered approach to the problem of NTDs due to its privileged position as a mediator.

As a matter of fact, a working paper issued by the TDR in 1979 [63] depicted the issue of Chagas disease as problem that derived from the lack of biomedical advancements. Instead, the possibilities of intervening and improving living and environmental conditions of affected groups and individuals were deemed in the same document as uncertain. Within the rationale of the TDR, uncertainty meant that the necessary path to attending to the problem of Chagas disease had to be pursued through a knowledgedriven approach led by biomedical sciences. This mode of reasoning was reproduced again in the justification of projects such as the TcGP in the 1990s, which explicitly envisaged the final elimination of Chagas disease within a time frame of ten years [55]. Although less explicit, these expectations may still live on through the unfulfilled promises of mainstream open science.

\section{Conclusions}

In this paper I suggested that the mainstream views on open science could be limiting the utilization of scientific knowledge in non-hegemonic contexts of science. These limiting approach to openness, I argued, is linked with restrictive conceptions of the dynamics of science and its products, which fail to account for the practices and processes involved in their production and use. From the case of drug development for neglected tropical diseases, I showed how different classes of resources and stakeholders actual, ideal or potential - become engaged or excluded in the process of turning scientific knowledge into socially usable outputs. To do so, I employed a set of critical conceptual tools developed in the field of science, technology, and society studies: one of these concepts revolved around the idea of cognitive exploitation, a concept that allows detecting how scientific outputs may be used in for-profit contexts by third-parties, but without objectively compensating the original producers; the other one revolved around the relations between centers and peripheries of science, proposing that less developed regions may take part in well-established international research network while at the same time fail to industrialize the scientific knowledge required to attend to local social needs.

While the development of genomic databases and the subsequent negotiations with pharmaceutical firms revealed no actual processes of exploitation to be taking place, the role of regulatory frameworks, intervening actors, and relations that shaped (and hindered) the dynamics of knowledge production did in fact play a role in enabling or disabling the utilization of outputs. In this sense, the backdrop of underlying issues did not just derive from access restrictions that stand as material or cognitive barriers; instead, political, legal, and symbolic resources possessed by mediators and intermediaries - such as pharmaceutical firms, international organizations, and regulatory agents - defined, too, asymmetrical positions in terms of acquiring and using scientific knowledge within the field of neglected tropical diseases research. These asymmetries stemmed, on the one hand, from the marked differences between international and local stakeholders. But on the other hand, they also stemmed from the differences between expert groups and the potential beneficiaries of knowledge - which in the case of neglected and poverty-related diseases coincide, respectively, with scientific elites and disenfranchised populations.

The central points developed here suggest, overall, that the capacities and the possibilities of participation need to be put in context and conceived as inseparable dimensions of open science and its implications for ownership, as they have a bearing on its potential to meet social needs in the non-hegemonic spaces of human activity. 


\section{Acknowledgement}

The author would like to thank the Open and Collaborative Science in Development Network (OCSDNet) for their support and contributions to this paper.

\section{References}

[1] P.J.J. Albajar-Vinas, Chagas disease in Europe, Euro Surveill (2011), pii:19975.

[2] A. Angheben, L. Boix, D. Buonfrate, F. Gobbi, Z. Bisoffi, S. Pupella et al., Chagas disease and transfusion medicine: A perspective from non-endemic countries, Blood Transfus 13(4) (2015), 540-550.

[3] Anonymous authority at the University of Liège [Interview]. Liège, Belgium, 2016 Dec 10.

[4] Anonymous laboratory director [Interview], San Martín, Argentina 2016 Jun 24.

[5] V. Arza and M. Fressoli, Benefits and obstacles of openness in science: An analytical framework illustrated with case study evidence from Argentina, Buenos Aires, 2016 [Internet], available from: https://stepsamericalatina.org/wp-content/ uploads/sites/21/2016/08/Arza-Fressoli_24082016.pdf.

[6] L. Basile, J.M. Jansa, Y. Carlier, D.D. Salamanca, A. Angheben, A. Bartoloni et al., Chagas disease in European countries: The challenge of a surveillance system, Euro Surveill 16 (2011), 1-10 [Internet], available from: http://www.ncbi.nlm. nih.gov/pubmed/21944556.

[7] D. Behague, C. Tawiah, M. Rosato, T. Some and J. Morrison, Evidence-based policy-making: The implications of globally-applicable research for context-specific problem-solving in developing countries, Soc Sci Med 69(10) (2009), 1539-1546. doi:10.1016/j.socscimed.2009.08.006.

[8] Y. Benkler, The Wealth of Networks: How Social Production Transforms Markets and Freedom, Yale University Press, Boston, Massachusetts, 2006.

[9] D.A. Benson, M. Cavanaugh, K. Clark, I. Karsch-Mizrachi, D.J. Lipman, J. Ostell et al., GenBank, Nucleic Acids Res 41(D1) (2013), D36-D42 [Internet], available from: https://academic.oup.com/nar/article-lookup/doi/10.1093/nar/ gks1195.

[10] BOAI, Budapest open access initiative, 2002 [Internet] [cited 2017 Jan 23], available from: http://www. budapestopenaccessinitiative.org/read.

[11] P. Bourdieu, El campo cientifico, REDES 1(2) (1994), 131-160.

[12] Callon and M. Some, Elements of a sociology of translation: Domestication of the scallops and the fishermen of St Brieuc Bay, Sociol Rev 32(1_suppl) (1984), 196-233 [Internet], available from: http://journals.sagepub.com/doi/10.1111/ j.1467-954X.1984.tb00113.x.

[13] J.M. Campanario, The peer review system: Many problems and few solutions. Rev española Doc Científica 25(3) (2006), $267-285$.

[14] F. Cobo, Infectious diseases in immigrant population related to the time of residence in Spain, J Immigr Minor Heal. 18(1) (2016), 8-15. doi:10.1007/s10903-014-0141-5.

[15] D.G. Codner, P. Becerra and D.A. Blind, Technology transfer or technological knowledge leakage: A case study from the South, J Technol Manag Innov 7 (2012), 184-195 [Internet], available from: http://www.scielo.cl/pdf/jotmi/v7n2/art15. pdf. doi:10.4067/S0718-27242012000200015.

[16] M. Cueto, Excelencia científicaca en la periferia, GRADE, Lima, 1989.

[17] A. Dolcemascolo and G. Yansen, Informational cognitive exploitation: Concealed relationships behind prosumers', activity on World Wide Web, Sociol Lav (145) (2017), 61-77.

[18] B. Fecher and S. Friesike, Opening science: One term, five schools of thought, in: Opening Science. The Evolving Guide on How the Internet Is Changing Research, Collaboration and Scholarly, S. Bartling and S. Friesike, eds, Springer International Publishing, Cham, 2014, pp. 17-48 [Internet] [cited 2014 Jul 30], available from: http://link.springer.com/10. 1007/978-3-319-00026-8.

[19] H. Ferpozzi, Coproducción de conocimientos y de problemáticas científicas: Dinámicas en la producción de conocimiento científico en la investigación genómica y biomédica sobre la enfermedad de Chagas (1993-2016), Unpublished doctoral dissertation, 2017.

[20] T. Hanrieder, Orders of worth and the moral conceptions of health in global politics, Int Theory 8(3) (2016), 390-421 [Internet], available from: http://www.journals.cambridge.org/abstract_S1752971916000099.

[21] M. Hardt and A. Negri, Postmodernization or the Informatization of Production. Empire, Harvard University Press, Cambridge, Massachusetts, 2001, pp. 280-303.

[22] D.A. Henderson, Eradication: Lessons from the past, Bull World Health Organ 76(2) (1998), 7-21.

[23] O. Horstick, Y. Tozan and A. Wilder-Smith, Reviewing dengue: Still a neglected tropical disease?, PLoS Negl Trop Dis United States 9(4) (2015), e0003632. doi:10.1371/journal.pntd.0003632. 
[24] V.H. Introducción, La ciencia periférica, Monte Ávila, Caracas, 1985.

[25] IUCN, Rules of procedure IUCN Red List assessment process 2013-2016, 2012 [Internet] [cited 2016 Aug 3], available from: http://jr.iucnredlist.org/documents/Rules_of_Procedure_for_Red_List_2013-2016.pdf.

[26] P. Kreimer, ¿Dependientes o integrados? La ciencia latinoamericana y la nueva división del trabajo, Nómadas 24 (2006), 199-212.

[27] P. Kreimer and Z.M. La, Explotación Cognitiva: Tensiones emergentes en la producción y uso social de conocimientos científicos, tradicionales, informacionales y laborales, in: Perspectivas Latinoamericanas en el Estudio Social de la Ciencia, la Tecnología y el Conocimiento, P. Kreimer, H. Vessuri, L. Velho and A. Arellano, eds, Siglo XXI, Mexico DF, 2014, pp. 178-193.

[28] P. Kreimer and J.P. Zabala, Chagas disease in Argentina: Reciprocal construction of social and scientific problems, Sci Technol Soc 12(1) (2007), 49-72 [Internet] [cited 2013 Sep 20], available from: http://sts.sagepub.com/cgi/doi/10.1177/ 097172180601200104.

[29] W. Lefèvre, Science as labor, Perspect Sci 13(2) (2005), 194-225 [Internet] [cited 2014 Feb 16], available from: http:// www.mitpressjournals.org/doi/abs/10.1162/106361405774270539.

[30] N. Leys Stepan, Eradication. Ridding the World of Diseases Forever? Cornell University Press, Ithaca, 2011, 312 pp.

[31] B. Liese, M. Rosenberg and A. Schratz, Programmes, partnerships, and governance for elimination and control of neglected tropical diseases, Lancet 375(9708) (2010), 67-76 [Internet], available from: http://linkinghub.elsevier.com/ retrieve/pii/S0140673609617499. doi:10.1016/S0140-6736(09)61749-9.

[32] M.P. Magarinos, S.J. Carmona, G.J. Crowther, S.A. Ralph, D.S. Roos, D. Shanmugam et al., TDR targets: A chemogenomics resource for neglected diseases, Nucleic Acids Res 40(D1) (2012), D1118-D1127 [Internet], available from: http:// nar.oxfordjournals.org/lookup/doi/10.1093/nar/gkr1053.

[33] H. Masum and R. Harris, Open source for neglected diseases: Magic bullet or mirage?, Washington, DC, 2011.

[34] D. McNeill and O.P. Ottersen, Global governance for health: How to motivate political change?, Public Health 129(7) (2015), 833-837 [Internet] [cited $2017 \mathrm{Jul}$ 21], available from: http://linkinghub.elsevier.com/retrieve/pii/ S0033350615001997.

[35] R.K. Merton, On Social Structure and Science, University of Chicago Press, Chicago, IL, 1966.

[36] D.H. Molyneux, The "neglected tropical diseases": Now a brand identity; responsibilities, context and promise, Parasit Vectors 5(1) (2012), 23 [Internet]. doi:10.1186/1756-3305-5-23.

[37] M. Nentwich and R. König, Cyberscience 2.0: Research in the Age of Digital Social Networks, Campus Verlag, Frankfurton-Main, 2012.

[38] C. Neylon, Openness in scholarship: A return to core values?, in: Proceedings of the 21st International Conference on Electronic Publishing: Expanding Perspectives on Open Science: Communities, Cultures and Diversity in Concepts and Practices, 2017 Jun 6-8, Limassol, Cyprus, IOS Press, Amsterdam, 2017, pp. 6-17 [Internet] [cited 2017 Dec 12], available from: http://doi.org/10.3233/978-1-61499-769-6-6.

[39] OANA, The Vienna principles: A vision for scholarly communication in the 21st century, Working Group "Open Access and Scholarly Communication" of the Open Access Network Austria (OANA), 2016 [Internet], available from: http:// viennaprinciples.org/v1/.

[40] M. Parker, K. Polman and A.T. Neglected, Tropical diseases in biosocial perspective, J Biosoc Sci 48(S1) (2016), S1-S15 [Internet], available from: http://www.journals.cambridge.org/abstract_S0021932016000274.

[41] J.A. Perez-Molina, A. Martinez Perez, F.F. Norman, B. Monge-Maillo and R. Lopez-Velez, Old and new challenges in Chagas disease, Lancet Infect Dis 15(11) (2015), 1347-1356. doi:10.1016/S1473-3099(15)00243-1.

[42] J.A. Perez-Molina, A. Perez-Ayala, P. Parola, Y. Jackson, S. Odolini and R. Lopez-Velez, EuroTravNet: Imported Chagas disease in nine European countries, 2008 to 2009, Euro Surveill 16(37) (2011), 1-5 [Internet], available from: http://www. ncbi.nlm.nih.gov/pubmed/21944557.

[43] I. Perrone, Internet y las publicaciones científicas, in: Internet: Políticas y Comunicación, E. Cafassi, ed., Biblos, Buenos Aires, 1998.

[44] S.M. Petersen, Loser generated content: From participation to exploitation, First Monday 13(3) (2008) [Internet] [cited 2014 Mar 31], available from: http://journals.uic.edu/ojs/index.php/fm/article/view/2141.

[45] W.B. Public, Participation in science and technology: Performing and obscuring a political-conceptual category mistake, East Asian Sci Technol Soc an Int J 1(1) (2007), 99-110 [Internet], available from: http://www.springerlink.com/index/ 10.1007/s12280-007-9004-7.

[46] J.C. Reeder and G.J.A. What, Have we learned from 40 years of supporting research and capacity building?, PLoS Negl Trop Dis 9(1) (2015), e3355 [Internet], available from: http://dx.plos.org/10.1371/journal.pntd.0003355.

[47] D.D. Reidpath, P. Allotey and S. Pokhrel, Social sciences research in neglected tropical diseases 2: A bibliographic analysis, Heal Res Policy Syst 9(1) (2011), 1-12 [Internet], available from: http://health-policy-systems.biomedcentral. com/articles/10.1186/1478-4505-9-1.

[48] R.G. Ridley, P. Ndumbe and R. Korte, Two years after the fourth external review: TDR moves forward with a new vision and strategy, PLoS Negl Trop Dis 2(11) (2008), 1-6. doi:10.1371/journal.pntd.0000307. 
[49] J. Rodriguez, Edición 2.0. Los Futuros del Libro, Melusina, Barcelona, 2007, 255 pp.

[50] E. Rullani, Le capitalisme cognitif: du déjà vu?, Multitudes 2(2) (2000), 87-94 [Internet] [cited 2014 Apr 2], available from: http://www.cairn.info/revue-multitudes-2000-2-page-87.htm.

[51] G.A. Schmunis, Epidemiology of Chagas disease in non-endemic countries: The role of international migration, Memórias do Inst Oswaldo Cruz 102(Suppl) (2007), 75-85 [Internet], available from: http://www.ncbi.nlm.nih.gov/ pubmed/17891282. doi:10.1590/S0074-02762007005000093.

[52] E.R. Sedyaningsih, S. Isfandari, T. Soendoro and S.F. Supari, Towards mutual trust, transparency and equity in virus sharing mechanism: The avian influenza case of Indonesia, Ann Acad Med Singapore 37(6) (2008), 482-488 [Internet], available from: http://www.ncbi.nlm.nih.gov/pubmed/18618060.

[53] J.J. Strasen, T. Williams, G. Ertl, T. Zoller, A. Stich and O. Ritter, Epidemiology of chagas disease in Europe: Many calculations, little knowledge, Clin Res Cardiol 103(1) (2014), 1-10 [Internet]. doi:10.1007/s00392-013-0613-y.

[54] The Netherlands EU Presidency, Amsterdam call for action on open science, Amsterdam, 2016 [Internet], available from: https://english.eu2016.nl/documents/reports/2016/04/04/amsterdam-call-for-action-on-open-science.

[55] The Trypanosoma Cruzi Genome Consortium, The Trypanosoma cruzi genome initiative, Parasitol Today 13(1) (1997), 16-22 [Internet], available from: http://linkinghub.elsevier.com/retrieve/pii/S0169475896100740.

[56] Time to remodel the journal impact factor, Nature 535(7613) (2016), 466 [Internet]. doi:10.1038/535466a.

[57] P. Trouiller, P. Olliaro, E. Torreele, J. Orbinski, R. Laing and N. Ford, Drug development for neglected diseases: A deficient market and a public-health policy failure, Lancet (London, England) 359(9324) (2002), 2188-2194 [Internet], available from: http://www.ncbi.nlm.nih.gov/pubmed/12090998.

[58] C. Vercellone, Plusvalía: una ley de explotación y de antagonismo, in: Capitalismo Cognitivo Renta, Saber y Valor en la época Posfordista, Prometeo, Buenos Aires, 2011, pp. 115-128.

[59] P. von Philipsborn, F. Steinbeis, M.E. Bender, S. Regmi and P. Tinnemann, Poverty-related and neglected diseases - an economic and epidemiological analysis of poverty relatedness and neglect in research and development, Glob Health Action 8(1) (2015), 25818 [Internet], available from: https://www.tandfonline.com/doi/full/10.3402/gha.v8.25818.

[60] J. Vuorinen, Ethical codes in the digital world: Comparisons of the proprietary, the open/free and the cracker system, Ethics Inf Technol 9(1) (2007), 27-38 [Internet], available from: http://link.springer.com/10.1007/s10676-006-9130-2.

[61] WHO, Research priorities for Chagas disease, human African trypanosomiasis and leishmaniasis, World Health Organization technical report series, 2012 [Internet], available from: http://www.ncbi.nlm.nih.gov/pubmed/23484340.

[62] G. Yamey, The world's most neglected diseases: Ignored by the pharmaceutical industry and by public-private partnerships, Br Med J 325(7357) (2002), 176-177 [Internet], available from: https://www.ncbi.nlm.nih.gov/pmc/articles/ PMC1123710/.

[63] J.P. Zabala, La enfermedad de Chagas en la Argentina. Investigación científica, problemas sociales y políticas sanitarias, Universidad Nacional de Quilmes, Bernal, 2010.

[64] M. Zukerfeld, Inclusive appropriation and the double freedom of knowledge: On the capitalist exploitation of non-for profit software, contents and data producers, Sociol Lav (133) (2014), 145-158. 